\title{
Organização da informação em narrativas infográficas na web voltadas para o processo de ensino-aprendizagem
}

\author{
Organization of information in infographics storytelling on \\ the web focused on the process of teaching and learning
}

Mariana Lapolli, Tarcísio Vanzin, Vania R. Ulbricht

narrativas infográficas, web, organização da informação, aprendizagem infographics storytelling, web, organization of information, learning

\begin{abstract}
As narrativas infográficas possibilitam a apresentação de conteúdos didáticos utilizando elementos com forte apelo visual. Associada à web, este recurso pode incorporar características como a interatividade, a multilinearidade, a multimidialidade, a convergência e a instantaneidade. Para evitar a sobrecarga cognitiva e a desorientação de navegação durante o processo de ensinoaprendizagem, a informação presente nas narrativas infográficas deve ser organizada. Neste sentido, esta pesquisa tem como objetivo verificar como a informação deve ser organizada com o intuito de contribuir para o processo de ensino-aprendizagem por meio de narrativas infográficas na web. A partir da pesquisa bibliográfica e das opiniões de especialistas na área de infografia, extraídas por meio de entrevistas semiestruturadas, caminhos são apontados para a elaboração de narrativas infográficas na web que possibilitem aos alunos recuperar, encontrar e visualizar facilmente as informações.
\end{abstract}

The infographic storytelling allows the presentation of educational content using elements with strong visual appeal. Associated to the web, this resource can incorporate features like interactivity, multilinearity, multimediality, convergence and immediacy. To avoid cognitive overload and disorientation navigation during the process of teaching and learning, the information in the infographic storytelling should be organized. In this sense, this research aims to determine how the information should be organized in order to contribute with the process of teaching and learning through infographic storytelling on the web. From the literature review and expert opinions in the area of infographics, extracted through semi-structured interviews, paths are pointed to the development of infographic storytelling on the web that allows students easily recover, find and visualize the information.

\section{Introdução}

As narrativas infográficas na web possuem grande potencial para o processo de ensino-aprendizagem, sendo que seus conteúdos são 
apresentados por meio de um forte apelo visual. Segundo Wojtkowski \& Wojtkowski (2002), com a tecnologia computacional é possível utilizar a visualização para contar histórias complexas. A utilização de histórias ajuda a estabelecer uma visão comum, motivando e ativando os indivíduos. (BURKHARD, 2005). O problema é que, muitas vezes, as informações recebidas não estão organizadas de maneira consistente, podendo requerer um tratamento posterior. A organização da informação surge neste contexto como uma forma de fazer com que as informações possam ser recuperadas, encontradas e visualizadas mais facilmente.

Assim, esta pesquisa visa verificar como a informação deve ser organizada com o intuito de contribuir para o processo de ensinoaprendizagem por meio de narrativas infográficas na web. Para alcançar o objetivo proposto, realizou-se uma pesquisa bibliográfica a partir de artigos científicos, teses, dissertações e livros técnicos. Para complementar esta investigação foram realizadas entrevistas semiestruturadas com especialistas na área de infografia. Assim, foi possível estabelecer um debate entre a teoria e as experiências práticas a respeito da organização das informações de conteúdos didáticos apresentados por meio de narrativas infográficas na web, no sentido de tornar essas informações compreensíveis aos alunos de um ambiente virtual de ensino-aprendizagem - AVEA.

\section{Procedimentos metodológicos}

Para este estudo, primeiramente foi realizada uma pesquisa bibliográfica, a partir do termo "organização da informação" e das combinações entre as palavras: narrativas, infografia, web e aprendizagem. A pesquisa foi realizada na base de dados Scopus e no Google Acadêmico. A partir da leitura dos resumos dos artigos científicos, teses e dissertações encontrados, foram selecionados aqueles que pertenciam ao escopo desta pesquisa. Nas referências dos trabalhos selecionados foram detectados autores e títulos de livros técnicos, sobretudo da área da infografia, que foram consultados para o desenvolvimento da presente investigação.

Após a pesquisa bibliográfica foram realizadas entrevistas semiestruturadas, que se trata de uma conversa a dois, realizada por iniciativa do entrevistador, com o desígnio de fornecer informações pertinentes a um objeto de pesquisa. (MINAYO, 1993). De acordo com Boni e Quaresma (2005, p. 75), “esse tipo de entrevista é muito utilizado quando se deseja delimitar o volume das informações, obtendo assim um direcionamento maior para o tema, intervindo a fim de que os objetivos sejam alcançados”. Para esta pesquisa, as entrevistas foram realizadas na Espanha, um dos países pioneiros no desenvolvimento e na pesquisa na área de infografia, sendo referência mundial nesse assunto. Os seis especialistas consultados foram: 
- Aitor Eguinoa: trabalhou em departamentos de infografia de jornais como El País (Espanha), El Correo (de Bilbao Espanha) e La Nación (Argentina). Professor da Faculdade de Comunicação da Universidade de Navarra (Espanha) e do Programa de Mestrado de Comunicação Multimídia da Universidad del País Vasco. É sócio de uma empresa que trabalha com o desenvolvimento de infografias e assessoria para a criação e organização de departamentos de infografia em empresas editoriais.

- Beatriz Elena Marín Ochoa: jornalista, professora da Universidade Pontifícia Bolivariana em Medellín (Colômbia). Doutora em comunicação e jornalismo pela Universitat Autònoma de Barcelona - UAB. Ministra disciplinas e possui diversas pesquisas publicadas na área da infografia, narrativas e novos meios da comunicação.

- Jordi Català: é pioneiro na infografia de imprensa na Espanha. Redator Chefe no jornal El Periódico de Catalunya, onde realiza reportagens escritas e visuais. Ganhou diversos prêmios de imprensa e infografia. É professor na UAB, na Escola Superior de Disseny i Enginyeria - ELISAVA e na Universitat Politècnica de Catalunya - UPF, ministrando disciplinas de infografia, comunicação visual, etc.

- José Luis Valero Sancho: professor do Departamento Comunicación Audiovisual y de Publicidad da UAB, um dos pesquisadores mais citados na área da infografia, tendo publicado papers, artigos e livros que versam sobre a temática, além de ter ministrado várias palestras e workshops sobre infografia digital.

- José Manoel de Pablos: doutor em Ciências da Comunicação, catedrático de jornalismo na Universidade de La Laguna (Espanha). Autor do livro "Infoperiodísmo: el periodista como creador de infografía", entre outros trabalhos sobre o tema da infografia.

- Mario Táscon: Um dos fundadores do jornal El Mundo. De 1991 a 1996 foi responsável pelo setor de infografia desse jornal, ganhando importantes prêmios internacionais. Foi diretor geral de conteúdos do grupo Prisacom, responsável pelas edições digitais do jornal El País. Professor da Universidade de Navarra. É sócio diretor de uma empresa que desenvolve, entre outros produtos para as novas mídias, trabalhos na área de infografia.

"A variedade de material obtido qualitativamente exige do pesquisador uma capacidade integrativa e analítica que, por sua vez, depende do desenvolvimento de uma capacidade criadora e intuitiva". (MARTINS, 2004, P. 293). Desta maneira, os dados coletados nas entrevistas foram tratados por meio de sua transcrição, organização e sintetização. A análise qualitativa desses dados foi realizada levando-se em consideração os trabalhos teóricos detectados na pesquisa bibliográfica. 


\section{Organização da informação}

Informação pode ser definida como dados dotados de relevância e propósito (DAVENPORT \& PRUSAK, 1999). De acordo com Garido (2011), esse conceito não é propriedade de nenhum campo de estudo em específico, mas de todos. Deste modo, a informação só existe quando tem sentido e significado para seus interlocutores.

Para tornar uma grande quantidade de informações facilmente acessível aos usuários, a informação necessita estar pré-estruturada, devendo comunicar algo ao público. Essa organização possibilita que as informações sejam recuperadas, encontradas e visualizadas mais facilmente. Neste sentido, Keller \& Tergan (2005) apontam a visualização como forma de ajudar na compreensão das relações entre as informações, bem como na busca visual pela informação relevante. Assim, o objetivo da visualização é representar graficamente informações a fim de facilitar a compreensão de conjunto de dados.

De acordo com Carvalho \& Marcos (2009), todas as aplicações orientadas à Visualização da Informação devem levar em consideração as características básicas de apreensão do sistema perceptivo humano como a cor, a forma, o tamanho, a noção de distância e o movimento. Para esses autores, quando combinadas e utilizadas de forma adequada, essas propriedades podem maximizar a percepção da informação. (CARVALHO \& MARCOS, 2009).

Com o avanço das tecnologias, torna-se possível "a construção de sistemas cada vez mais complexos, que podem oferecer informações mais precisas e ricas em relação a sua qualidade de apresentação ao utilizarem recursos gráficos semelhantes aos do mundo real”. (DIAS, 2007, P.7). Portanto, metáforas visuais adequadas devem ser utilizadas com a finalidade de transmitir a informação de forma clara e rápida, evitando a sobrecarga de informações.

As metáforas visuais ajudam as pessoas a entender e navegar pelo mundo virtual de maneira mais amigável. Elas são constituídas por imagens e conceitos que remetem a elementos do mundo real, baseados nas experiências anteriores dos intérpretes. Como exemplo disto, é possível citar as metáforas presentes no desktop dos computadores. "As metáfora de papéis, arquivos, pastas, cestas de lixo, entre outras, tentam transpor ao ambiente gráfico dos sistemas operacionais uma representação de elementos comuns ao mundo analógico, que já estavam profundamente enraizados no dia-a-dia dos trabalhadores pelo mundo todo". (OLIVEIRA, 2005, P. 43). 


\section{Narrativas infográficas na web}

Nas narrativas infográficas, caracterizadas pela associação de imagens e textos simples e objetivos, as informações são organizadas de maneira que o intérprete possa visualizar aquilo que é mais importante. Deste modo, da mesma forma que a contribuição do interprete é necessária para a compreensão das representações gráficas, a contribuição da infografia é necessária, uma vez que ela deve conter certa estética, fácil compreensão, iconografia, tipografia e tamanho apropriado. (VALERO SANCHO, 2000).

A utilização e os estudos relativos a esse recurso ganhou destaque no campo no jornalismo. Entre os diversos pesquisadores que se dedicaram a este tema é possível citar: De Pablos, 1998; Peltzer, 2001; Valero Sancho, 2001; Cairo, 2008; Teixeira, 2010 e; Moraes, 2013. Para De Pablos (1998), a infografia se trata de uma antiga fórmula humana para comunicar informações, cujo surgimento remete ao início da comunicação humana, antes da fala.

As maneiras de elaborar as infografias e publicá-las mudaram ao longo dos anos. As representações visuais tornaram-se cada vez mais complexas, sobretudo com a ampliação da internet. Segundo Rodrigues (2009), no ciberespaço são necessárias técnicas e aplicativos avançados que favoreçam uma produção não mais estática, mas com elementos dinâmicos e ferramentas apropriadas para que a infografia gere imagens em movimento e animações, que estimulem um cenário ancorado nas potencialidades da hipermídia.

De acordo com Táscon (2013), a infografia na web possui mais possibilidades que a impressa. Para este especialista, a infografia impressa aparece em uma página que apresenta outros conteúdos ao redor, enquanto que a interativa pode conter todos os conteúdos nela mesma e, além disso, pode ser inserida num entorno que o contexto mude.
Não é como num jornal ou num livro que (a infografia) está sempre associada a página que está impressa. A infografia interativa pode ser um bloco que logo visualizamos fora da página ou em outro dispositivo [...]. Sozinha tem que ser compressível como se estivesse em contexto. Em geral este tipo de infografia, que não é complemento, é um storytelling em si mesma. Uma narrativa em si mesma. Não deveria depender dos elementos exteriores. (TÁscon, 2013).

Marín Ochoa (2009a) afirma que a infografia na web aproveita as possibilidades de integração de recursos que incluem textos, ícones (próprios da simbologia e do grafismo), elementos visuais (na fotografia, presentes na televisão e no cinema) e sons (silencio e ruídos), bem como ferramentas informáticas e programas apropriados. Assim, "a infografia se destaca pela capacidade de integração de formatos diferenciados de conteúdo e de articulação visual da narrativa”. (RIBAS, 2005, P.129). 
As representações e explicações verbais e visuais presentes na estrutura de apresentação do infográfico necessitam ser organizadas em alguma sequência. Assim, o infográfico precisa ser narrado e a decodificação de fácil entendimento depende da forma como esta narrativa é estruturada. (BECKER, 2010, P. 4).

Destarte, as diferentes maneiras de se apresentar visualmente as informações num infográfico na web, compõem narrativas que podem ser contadas por meio de diferentes linguagens. De acordo com Valero Sancho (2003), não é possível dizer quais formas ou conteúdos são capazes ou não de atender às necessidades de uma história. A criatividade aliada à noção a respeito das características e das etapas de elaboração de uma infografia na web contribui para que as informações sejam apresentadas de forma que os usuários sejam capazes de assimilá-las de maneira efetiva, possibilitando a aquisição de novos conhecimentos.

As etapas de elaboração de uma narrativa infográfica na web envolvem diferentes passos (Figura 1) que devem ser acompanhados por um coordenador ou responsável, garantindo o bom desenvolvimento do trabalho.

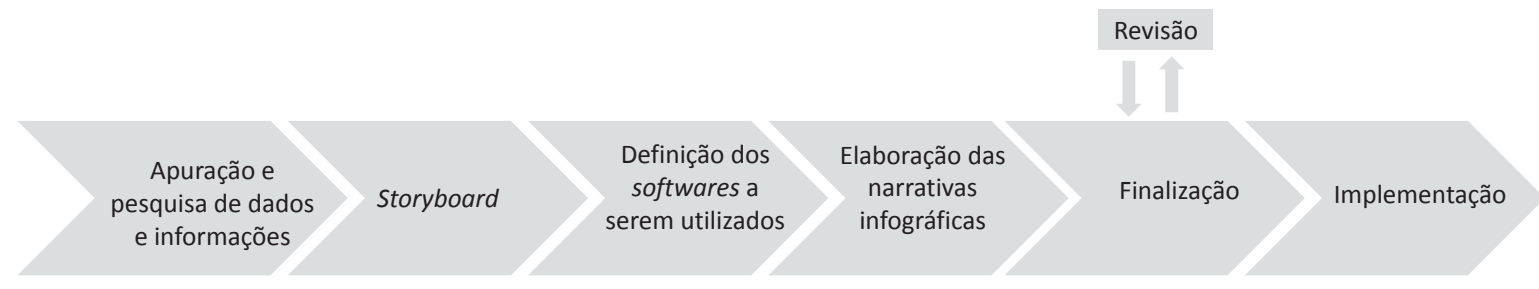

Figura 1 Etapas de elaboração de uma narrativa infográfica na web

Moraes (2013, P.68) diz que "em cada etapa, deve-se avaliar a produção em relação ao objetivo que deve ser alcançado no trabalho e avançar somente em caso positivo. Se a avaliação não for positiva, a equipe deve voltar e corrigir os pontos negativos para só então avançar". Esse autor discorre sobre as etapas de produção de uma infografia impressa, no entanto, o mesmo cuidado deve ser tomados quando se está elaborando uma narrativa infográfica na web.

De acordo com Eguinoa (2013), o mais importante na elaboração de uma narrativa infográfica na web é a obtenção das informações por meio de boas fontes, bem como a organização e a estruturação das mesmas. Para esse profissional, o trabalho fundamental acontece antes da equipe de elaboração sentar na frente do computador. Nesta etapa, muitas decisões devem ser tomadas: como que história será contada, que tipo de interação haverá, como será acessada, quais meios que serão utilizados, entre outras, antes de eleger o programa que será utilizado para o desenvolvimento do infográfico. Tudo isto é realizado por meio de um storyboard.

O storyboard é a captura das ideias criativas que se tem acerca de um projeto de infografia, servindo para se ter uma ideia aproximada 
do conteúdo e da forma que terá o produto final. (VALERO SANCHO, 2001). Este esboço pode ser feito sobre uma folha de papel ou em algum programa do computador, organizando a informação de maneira que seja compreensível pelo intérprete.

Para infografias não lineares, Cairo (2008) sugere a confecção de um storyboard parecido com os galhos de uma árvore. Independente do formato, o importante é ter um instrumento bem elaborado que permita o diálogo entre os participantes da equipe de desenvolvimento da narrativa infográfica na web. Esta equipe é caracterizada por sua multidisciplinaridade.

\section{Narrativas infográficas na web voltadas para o processo de ensino-aprendizagem}

Lapolli et al. (2013a) propõem a utilização de narrativas infográficas na web durante o processo de ensino-aprendizagem. Para definir os conteúdos a serem apresentados, é essencial a participação de professores e/ou pesquisadores da disciplina a ser estudada, bem como a diferentes materiais que possam contribuir nesta etapa. Um especialista em comunicação visual também se faz importante, uma vez que ele é capaz de determinar a estética e a interface mais apropriadas de acordo com o conteúdo e o público ao qual o material é destinado. (FLORES, 2009).

Nas narrativas infográficas na web, a ordem e o ritmo de apresentação podem ser determinados pelo aluno, possibilitando que o processo de ensino-aprendizagem ocorra de maneira mais fluida e de acordo com o ritmo de cada um. Além disso, a diversidade de recursos comunicativos que podem ser inseridos nesta ferramenta permite que os alunos acessem os conteúdos de acordo com suas preferências. Segundo Marín Ochoa (2009b), as características da infografia digital permitem que ela contenha diversos gêneros, formas de apresentação, meios, pontos de vista e possibilidades de interação que a transformam numa ferramenta ideal para a aprendizagem no século XXI.

Para Bottentuit Junior, Lisboa \& Coutinho (2011), a utilização de infográficos promove uma aprendizagem onde os alunos podem se deparar com uma realidade mais consistente. Neste sentido, Andrade (2011, p. 66) alega que. "[...] a infografia busca uma aproximação do estudante ao objeto de estudo, provocando uma experiência interativa mais profunda e significativa, trazendo uma informação muitas vezes distante da realidade de todos, de uma forma clara e compreensível".

Valero Sancho (2012) enxerga a infografia digital como uma das melhores formas de ensinar devido às múltiplas ferramentas que podem ser utilizadas a seu serviço, conduzindo os estudantes pelos caminhos da aprendizagem. Sob o pretexto didático, frequentemente são apresentadas ficções ou simulações que não ocorreram e nunca ocorrerão com a finalidade de construir uma realidade utópica ou 
de mostrar as qualidades de alguma coisa. (VALERO SANCHO, 2012). "Entretanto, não é qualquer tipo e forma de material educacional que os alunos buscam. Eles querem materiais atrativos visualmente, que consigam interagir, conversar, compreender com facilidade e estimule suas reflexões”. (BRAGA, 2009, P. 7).

A aprendizagem, neste contexto, ocorre por meio da colaboração e da interação social formando comunidades de prática virtuais. Essas comunidades interligam pessoas com interesses em comum, destacando-se como facilitadoras do processo comunicacional. Nos espaços virtuais, pessoas que possuem interesses em comum têm a possibilidade de se encontrar e estabelecer relações, independente de sua posição geográfica. Mesmo estando distribuídos no âmbito do ciberespaço, os membros de uma comunidade virtual compartilham e formam teias de relações pessoais. Neste sentido, Corrêa (2004, p.7) afirma que a principal peculiaridade das comunidades virtuais "é o fato de surgir de forma espontânea, quando se estabelecem agrupamentos sociais com base em afinidades. Assim, as CoPs Virtuais, organizam grupos desterritorializados e intemporais que se utilizam da rede e de AVEAs para a construção coletiva de conhecimento.

Bezerra, Serafim \& Medeiros (2011) afirmam que na modalidade de Educação a Distância, construir e compartilhar conhecimento por meio da infografia torna um objeto de interesse individual em algo passível a discussão e construção coletiva. Assim sendo, as narrativas infográficas na web são objetos potencialmente passíveis de tornarem-se alvo de discussões em Comunidade de Prática.

Com a finalidade de possibilitar que as narrativas infográficas na web sejam exploradas de forma intuitiva pelos alunos, seus dados e informações devem ser devidamente organizados e apresentados, focando suas energias naquilo que é relevante. Costa, Tarouco \& Biazus (2011) abordam a escolha e a criação de imagens para conteúdos educacionais, enfatizando que as imagens meramente decorativas não contribuem para a compreensão do conteúdo e podem inclusive aumentar a carga cognitiva do estudante, prejudicando a aprendizagem.

Para Valero Sancho (2010), as infografias digitais possuem um forte componente estético que seduz e capta a atenção dos intérpretes. Essas apresentações sedutoras e de fácil assimilação, que utilizam imagens, metáforas visuais, textos, cores, entre outros, motivam a entrada nos diversos conteúdos de forma fácil. Segundo o especialista, "funciona mais o simples em forma e em conteúdo. Utilizando, sempre que necessário, a metáfora [...]. Mas a metáfora tem que ser simples também e todos tem que entendê-la”. (Valero Sancho, 2013). Assim, as narrativas infográficas não devem ser muito complexas em relação a sua profundidade e a quantidade de grafismos por tela. Em entrevista, Valero Sancho (2013) expõe que se o documento for muito denso, não funciona. Neste sentido, Aitor Eguinoa (2013) afirma que "[...] nós comprovamos que quanto menos densa for a infografia, as pessoas preferem porque as compreendem em sua totalidade". Para 
este especialista, se a informação não é encontrada é porque ela está escondida atrás de um ícone que não foi visto ou porque o conteúdo está muito resumido. Deste modo, uma frustração é criada no intérprete fazendo com que ele vá perdendo o interesse no infográfico. "Então é melhor otimizá-lo ou separá-lo para que tu vás adquirindo informação de maneira gradual”. (EGUINOA, 2013).

Para organizar as informações de maneira que sejam facilmente percebidas e decodificadas pelos alunos, Valero Sancho (2013) sugere que haja uma tela de entrada estética numa narrativa infográfica na web, que ao ser clicada direcione o usuário para uma tela principal. Esta tela principal deve conter os links para acessar os conteúdos pedagógicos, sendo que a informação deve estar hierarquizada de modo que o aluno acesse primeiramente os conteúdos mais simples, para depois poder acessar os mais complexos. Para Valero Sancho (2013), os ícones têm que ser rápidos e facilmente reconhecíveis. "Tens que fazer uma icônica que se entenda rápido e facilmente. Contextualmente tu tens que fazer com que isto seja reconhecível no mundo". (VAlero SANCHo, 2013). Para Eguinoa, os ícones têm que dar pistas de para que servem, estando relacionados ao que vai acontecer quando clicado, caso contrário, não convida o aluno a entrar ou cria uma frustração.

\footnotetext{
Se eu aperto e não ocorre o que eu espero, me desorienta e faz com que eu perca a concentração. E se o que estamos explicando é uma coisa complexa, $[. .$.$] não é fácil de entender. Tudo isso são barreiras$ que estamos colocando que dificultam a transmissão da informação. (Eguinoa, 2013).
}

Para Marín Ochoa (2013), por trás de cada link há uma aprendizagem, um conhecimento que é implícito e se torna mais explícito a medida que o aluno se aprofunda nele. A especialista define infografia como imagem sintética, na qual menos é mais. De acordo com Valero Sancho, as narrativas infográficas devem ter menos textos e a imagem deve ser mais bem organizada. Para o especialista, é preciso evitar o máximo de texto possível, colocando apenas um título ou um texto explicativo em cada tela da narrativa infográfica para que o aluno saiba qual o objetivo de cada lâmina.

Uma infografia tem que permitir que se entenda tudo sem necessidade de ler. Se não, não é uma boa infografia. Se tu tens que colocar muito texto, então não estás conseguindo o que buscas com a infografia. Infografia tem que te permitir a didática por si mesma. Que aquilo funcione de maneira simples sem grandes necessidades de explicações. Na medida em que se tem que explicar com textos ou com voz, estamos tendo um problema com a imagem. (Valero Sancho, 2013).

Assim, o desenvolvedor de uma narrativa infográfica na web deve estar atento ao uso de estéticas desnecessárias, devendo evitá-las. 
(VAlero SANCho, 2013). De Pablos (2013) corrobora ao dizer que "menos é mais" e que as ilustrações devem ser o mais simples possível. Outro fator importante é a tipografia das narrativas infográficas na web que, segundo Català deve ser utilizada como um desenho a mais ou uma imagem.

A letra se tu a convertes, a hierarquizas, lhe dás tons de cinza, de preto, fazes jogos tipográficos, uns em caixa alta, outros em caixa baixa, uns maiores e uns menores, estás convertendo também em visual. Estás redesenhando o visual e estás fazendo-o atrativo. (Català, 2013).

Tudo isso contribui para a organização das informações nas narrativas infográficas na web voltadas para o processo de ensinoaprendizagem. A eficácia da utilização deste tipo de material é enfatizada pelos especialistas entrevistados. Por exemplo, Eguinoa (2013) percebe o apoio da comunidade educativa que consideram as narrativas infográficas como uma ferramenta muito útil, que comunica a seus alunos.

A infografia é uma ferramenta muito útil para a educação de qualquer tipo de pessoas, de qualquer aluno e de qualquer idade. Visualmente compreendemos muito melhor as informações, temos maior capacidade de reter, de memorização. A interatividade, os recurso online, nos dá muita capacidade para adaptar os conteúdos a cada nível de aprendizagem. (Eguinoa, 2013).

Para Català (2013) a infografia traduz informações em imagens, permitindo que os conceitos sejam assimilados muito mais rápido do que a leitura de um texto escrito. "Uma informação visual acompanhada de texto é uma informação imediata [...] organizar, hierarquizar, sintetizar tudo isso e estabelecer uma relação, te simplifica a reflexão". (CATALÀ, 2013). Corroborando com isso, Marín Ochoa (2013) diz que a infografia é uma forma de adquirir e transmitir conhecimentos, sendo que sua linguagem sintética e visual propicia a aprendizagem. Além disso, para a especialista, a infografia pode estimular a curiosidade e a criatividade, despertando o desejo das pessoas de conhecer mais.

\section{Considerações Finais}

Nesta pesquisa foi verificado como a informação deve ser organizada com o intuito de contribuir para o processo de ensino-aprendizagem por meio de narrativas infográficas na web. Na pesquisa bibliográfica foram encontrados trabalhos que apontam caminhos para a elaboração deste tipo de material, de forma que os alunos possam facilmente recuperar, encontrar e visualizar as informações. Para que isto ocorra, 
é necessário que a equipe de desenvolvimento esteja atenta às etapas de elaboração de uma narrativa infográfica na web, desenvolvendo de forma mais detalhada possível, um storyboard que possibilite o diálogo entre a equipe multidisciplinar. Nas entrevistas, os especialistas na área de infografia reforçam aquilo que é dito na teoria e apontam procedimentos que devem ser realizados na prática para que se obtenha como resultado um material no qual as informações estejam bem organizadas e apresentadas de forma apropriada para os alunos de um AVEA.

Ao levar em consideração todos os pontos levantados nesta pesquisa, torna-se possível à equipe de elaboração de narrativas infográficas na web realizar um trabalho que promova o processo de ensino-aprendizagem. Tudo isso, aproveitando aquilo que as narrativas infográficas na web oferecem que é a possibilidade de utilizar uma linguagem sintética, visual, interativa, multilinear e multimídia, despertando a curiosidade, a criatividade e a vontade de conhecer dos participantes de uma comunidade virtual voltada para o processo de ensino-aprendizagem.

A partir do exposto, abrem-se caminhos para futuros trabalhos que abordem o tema infografia associado ao processo de ensinoaprendizagem, que é um tema ainda pouco explorado na ciência.

\section{Agradecimento}

À Coordenação de Aperfeiçoamento de Pessoal de Nível Superior CAPES pelo apoio no subsídio desta pesquisa.

\section{Referências}

ANDRADE, R. DE O. (2011). Infografia educacional: uma análise sobre seu potencial pedagógico e aplicação no ensino. Monografia - Programa de Pós-Graduação em Design Informacional, Pontifícia Universidade Católica do Paraná, Curitiba. BECKER, C. v. Narrativas gráficas: uma (re)descoberta da leitura. In: anais do II Congresso Internacional de Leitura e Literatura Infantil e Juvenil / I Fórum Latino Americano de Pesquisadores da Leitura. Porto Alegre: Pontifícia Universidade Católica do Rio Grande do Sul, 2010. Disponível em: <http://ebooks. pucrs.br/edipucrs/anais/IICILLIJ/4/CarolineVBecker.pdf>. Acesso em: 09 jul. 2013.

BEZERRA, C. C. \& SERAFIM, M. L. (2011). Infografia como alternativa para o Ensino a Distância. Hipertextus Revista Digital, n. 6, Ago. Disponível em: <http:// www.hipertextus.net/volume6/Hipertextus-Volume6-Carolina-CavalcantiBezerra_Maria-Lucia-Serafim_Laercia-Maria-Medeiros.pdf>. Acesso em: 09 jul. 2013.

BOTTENTUIT JUNIOR, J. B.; LISBOA, E. S. \& COUTINHO, C. P. (2011). O infográfico e as suas potencialidades educacionais. In: IV Encontro Nacional de Hipertexto e Tecnologias Educacionais. Sorocaba.

BRAGA, C. S. (2009). O Infográfico na Educação a Distância: uma contribuição para 
Lapolli, M. Vanzin, T. \& Ulbricht, V.R. | Organização da informação em narrativas infográficas na web voltadas para o processo de ensino-aprendizagem

a aprendizagem. In: $15^{\circ}$ Congresso Internacional ABED de Educação a Distância, Fortaleza.

BURKHARD, R. A. (2005). Strategy Visualization: A New Research Focus in Knowledge Visualization and a Case Study. In: Proceedings of I-KNOW '05 Graz: 528-534, Austria.

CAIRO, A. (2008). Infografia 2.0: visualizacion interactiva de informacion en prensa. Espanha: Alamut.

CARVAlHO, E. S. \& MARCos, A. F. 2009. Visualização de informação. Guimarães: Centro de Computação Gráfica.

CATALÀ, s. (2013). Entrevista semiestruturada sobre as narrativas infográficas desenvolvidas. Entrevista concedida a Mariana Lapolli, em 12 de dez.

CORRÊA, H. W. C. Comunidades virtuais gerando identidades na sociedade em rede. In: Revista do Programa de Pós-Graduação em Comunicação da Universidade Federal Fluminense, n.13, 2007.

Costa, v. M. DA; TAROUCO, L. M. R. \& BiAZus, M. C. v. (2011). Criação de Objetos de Aprendizagem baseados em infográficos. Disponível em: <http://laclo2011. seciu.edu.uy/publicacion/laclo/laclo2011_submission_68.pdf>. Acesso em: 10 fev. 2013.

DAVENPORT, T. \& PRUSAK, L. (1999). Conhecimento empresarial. Rio de Janeiro: Campus.

DE PABLOS, J. M. (1998). Siempre ha habido infografia. In: Revista Latina de Comunicación Social, La Laguna, Tenerife, n. 5. Disponível em: <http://www.ull. es/publicaciones/latina/a/88depablos.htm>. Acesso em: 10 fev. 2012.

. (2013). Entrevista semiestruturada sobre as narrativas infográficas desenvolvidas. Entrevista concedida a Mariana Lapolli, em 05 de dez.

DIAS, M. P. (2007). A contribuição da visualização da informação para a ciência da informação. Dissertação (Mestrado) - Programa de Pós-Graduação em Ciência da Informação, Pontifícia Universidade Católica de Campinas, Campinas.

EGUINOA, A. (2013). Entrevista semiestruturada sobre as narrativas infográficas desenvolvidas. Entrevista concedida a Mariana Lapolli, em $17 \mathrm{de} \mathrm{dez.}$

FLORES, F. C. (2009). La Ciudad del Gobernador: Módulo digital de aprendizaje basado en infografías interactivas para materias de segundo año medio. In: Proyecto para optar al Título Profesional de Diseñador con mención en Diseño Gráfico, Universidad de Chile - Facultad de Arquitectura y Urbanismo - Escuela de Diseño. Santiago. Disponível em: <http://www.tesis.uchile.cl/bitstream/handle/2250/111165/caceres_f.pdf?sequence=1>. Acesso em: 23 jul. 2013.

GARRIDO, I. DOS s. (2001). Organização da Informação: uma análise conceitual. Disponível em: <http://pt.slideshare.net/doritchka/organizao-da-informao-uma-anlise-conceitual-2011>. Acesso em: 15 fev. 2014.

KELLER, T. \& TERGAN, S-O. (2005). Visualizing knowledge and information: An introduction. In: Tergan, S-O. \& Keller, T. Knowledge and information visualization: searching for synergies: 1-23. Tübingen, Germany: Springuer.

LÜDKE, M. (1986). Pesquisa em educação: abordagens qualitativas. São Paulo: EPU. MARÍN OCHOA, B. E. . (2009A). La infografía digital, una nueva forma de comunicación. Tese (Doutorado) - Faculdad de Ciencias de la Comunicación, Universidad Autónoma de Barcelona, Barcelona.

. (2009B). La infografía digital: género periodístico y recursos pedagógico. 
Lapolli, M. Vanzin, T. \& Ulbricht, V.R. | Organização da informação em narrativas infográficas na web voltadas para o processo de ensino-aprendizagem

In: Actas de la $3^{\text {a }}$ Conferencia ACORN-REDECOM, Ciudad de México. (2013). Entrevista semiestruturada sobre as narrativas infográficas desenvolvidas. Entrevista concedida a Mariana Lapolli, em 03 de dez.

Martins, H. H. T. DE S. Metodologia Qualitativa de Pesquisa. Educação e Pesquisa, São Paulo, v.30, n.2: 289-300, maio/ago. 2004.

minaYo, M. C. DE S. O desafio do Conhecimento. São Paulo: Hucitec, 1993. MORAES, A. (2013). Infografia: história e projeto. São Paulo: Blucher.

OLIVEIRA, L. B DE. (2005). Arquitetura da Informação aplicada na construção de um sistema publicador para Jornais Digitais. Dissertação (Mestrado) - Programa de Pós-graduação da Escola de Comunicação e Artes da Universidade de São Paulo, São Paulo.

PELTZER, G. (1991). Jornalismo Iconográfico. Lisboa: Planeta.

RIBAS,B. (2005). A narrativa webjornalística: um estudo sobre modelos de composição no ciberespaço. Dissertação (Mestrado) - Programa de Pós-Graduação em Comunicação e Cultura Contemporâneas, Faculdade de Comunicação, Universidade Federal da Bahia, Salvador.

RODRIGUES, A. V. (2009). Infografia Interativa em base de dados no jornalismo digital. Dissertação (Mestrado) - Programa de Pós-Graduação em Comunicação e Cultura Contemporâneas, Universidade Federal da Bahia, Salvador.

TÁsCon, M. (2013). Entrevista semiestruturada sobre as narrativas infográficas desenvolvidas. Entrevista concedida a Mariana Lapolli, em 13 de dez.

TEIXEIRA, T. 2010. Infografia e Jornalismo: conceitos, análises e perspectivas. EDUFBA: Salvador.

VAlero SANCHO, J. L. (2000). La infografia de prensa. In: Revista Latina de Comunicación Social: 121-131.

(2011). La infografia: técnicas, análisis y usos periodísticos. Disponível em: <http://books.google.com.br/books?hl=pt-BR\&lr=\&id=mJ0RgAT8guMC \&oi=fnd\&pg=PA11\&dq=VALERO+SANCHO,+Jos\%C3\%A9+Luis.\&ots=yI9d2 mR7P\&sig=GEtL7WamEeNzqqcZ13UCC8BMgs4\#v=onepage\&q\&f=false>. Acesso em: 05 dez. 2011.

(2003). El relato em la infografía digital. In: Noci, J. D. \& Aliaga, R. S. (Coords.) Manual de Redacción Ciberperiodística. Barcelona: Editorial Ariel. (2010). La comunicación de contenidos en la infografía digital. In: Estudios sobre El Mensaje Periodístico, v. 16: 469-483.

(2012). Infografía Digital: la visualización sintética. Barcelona: Boch. (2013). Entrevista semiestruturada sobre as narrativas infográficas desenvolvidas. Entrevista concedida a Mariana Lapolli, em 22 de nov.

WOJTKOWSKI, W.; WOJTKOWSKI, W. G. 2002. Storytelling: its role in information visualization. In: European Systems Science Congress.

\section{Sobre os autores}

\section{Mariana Lapolli}

$<$ marilapolli@gmail.com>

Doutora, Universidade Federal de Santa Catarina, graduada em

Comunicação Social - Publicidade e Propaganda, mestre e doutora 
em Engenharia e Gestão do Conhecimento. Participante do grupo de pesquisa Web GD Acessível, com apoio da CAPES e CNPq. Tem publicado pesquisas nas áreas de novas mídias, narrativas, infografia, etc.

\section{Tarcísio Vanzin}

<tvanzin@gmail.com>

Doutor, Universidade Federal de Santa Catarina, mestre e doutor em Engenharia de Produção pela UFSC. É professor associado nos cursos de Arquitetura e Urbanismo e Sistemas de Informação, professor colaborador do Programa de Pós-graduação em Arquitetura e Urbanismo e professor permanente do PPEGC da UFSC.

\section{Vania Ribas Ulbricht}

$<$ ulbricht@floripa.com.br>

Doutora, Universidade Federal de Santa Catarina, mestre e doutora em Engenharia de Produção. Professora visitante da UFPR de PósGraduação em Design. Pesquisadora da Université Paris 1 (PanthéonSorbonne)> Presta serviço voluntário no PPEGC da UFSC. Bolsista em Produtividade e Desenvolvimento Tecnológico e Extensão Inovadora - DT 2009/CNPq.

Artigo recebido em 22 abr. 2014, aprovado em 03 jul. 2014. 